\title{
Deleuze e Guattari: a noção de processos de subjetivação.
}

\author{
Jorge Alberto Rocha ${ }^{1}$ \\ UEFS-Ba/Brasil \\ jorgeacr@terra.com.br \\ Deivison Warlla Miranda Sales ${ }^{2}$ \\ UEFS-Ba/Brasil \\ deivisonpsi@icloud.com
}

Recibido 19/06/2018

Aprobado $1 / 08 / 2018$

\section{Resumo}

La cuestión del sujeto y de la identidad del yo a partir de la Edad Moderna se ha convertido en un tema nuevo y central, en las palabras de Merleau-Ponty. Para dar cuenta de este problema el pensamiento de Deleuze y de Guattari proporcionaron una perspectiva muy interesante, a la vez bastante diferente de la que encontramos desde aquella tradición. Así, los autores trabajaron con nociones como territorialización, rizoma ..., buscando evidenciar que el yo o el sujeto no se da a partir de identidades, sino de diferencias, de encuentros. En fin, ¿cómo comprender la noción de procesos de subjetivación?

\section{Abstract}

The question of the subject and the identity of the self from the Modern Age has become a new and central theme, in the words of Merleau-Ponty. To deal with this problem the thought of Deleuze and Guattari provided a very interesting perspective, at the same time quite different from the one we have found since that tradition. Thus, the authors will work with notions such as territorialization, rhizome ..., seeking

\footnotetext{
${ }^{1}$ Jorge Alberto Rocha é professor Adjunto de Filosofia na Universidade Estadual de Feira de SantanaBa./Brasil, sendo mestre em Filosofia pela Unicamp e Doutor em filosofia pela UFBa.

2 Deivison Warlla Miranda Sales é graduado em Psicologia pela Universidade Federal do Piauí e faz Especialização em Filosofia Contemporânea na UEFS-Ba/Brasil.
} 
to show that the self or the subject is not given from identities, but from differences. Finally, how to understand the notion of subjectivation processes?

\section{Palavras-chave}

Deleuze; Guattari; Rolnik, sujeito; processos de subjetivação;

\section{Keywords}

Deleuze; Guattari; Rolnik, subject, subjectivation processes;

\section{Introdução}

Onde o tema da "subjetividade" começa a ser tratado na filosofia? Em Singnes Merleau-Ponty enumera essa aventura, cuja data remonta a autores da Idade Moderna. Assim, houve o "Eu que Montaigne amava acima de tudo", enquanto Pascal o odiava; o "eu" que "pensa" neste autor e em Descartes; o "eu" de Rousseau, mistura de inocência e culpabilidade; o sujeito transcendental dos kantianos, o de Biran e o de Kierkegaard: neste último caso, um "eu" que não se bastava como sobrevôo intelectivo de si, de uma essência-Ser posta de uma vez por todas, senão de um "eu" constituído na trama da sua vida (MERLEAU-PONTY, 1991, p. 166-167).

Olhemos mais de perto o caso de Descartes. Em Meditations ele a certo momento descobre a verdade há tempos procurada: "Eu sou, eu existo: isto é certo; mas por quanto tempo? A saber, por todo o tempo em que eu penso". Logo a seguir ele esclarece a natureza desse eu pensante, res cogitans: “Que é uma coisa que pensa? É uma coisa que duvida, que concebe, que afirma, que nega, que quer, que não quer, que imagina também e que sente" (DESCARTES, 1979, p. 94-95).

Para Merleau-Ponty, sem termos a necessidade de evocar cada pensador acima citado, tanto a subjetividade como tema filosófico vai aparecer a partir da Idade Moderna, quanto uma linha geral vai estar presente naqueles autores. Sobre o primeiro ponto escreve Merleau-Ponty: 
Uma vez que sobrevinda a reflexão, uma vez pronunciado o "'eu penso", o pensamento de ser tornou-se de tal modo nosso que, se tentarmos expressar o que o precedeu, todo o nosso esforço conseguirá apenas propor um cogito préreflexivo (MERLEAU-PONTY, 1991, p.167).

Quanto ao segundo aspecto, ainda que relacionado com as suas preocupações de restituir o ser pensante ao mundo-da-vida, encarnando, corporificando aquele ser que era só pensamento: quem eu sou verdadeiramente? "Eu sou meu corpo (...) "não uma reunião de partes e também a experiência de sua degradação na morte" (MERLEAU-PONTY, 1971, p. 434) -a ideia de um eu pleno a partir do século XVII ainda persiste, uma vez que, "estrangeiro ao mundo", fala-se da presença de um "eu" diante da sua natureza:

“...sejam quais forem as suas discordâncias, os modernos têm em comum a ideia de que o ser da alma ou o ser-sujeito não é um ser menor, que talvez seja a forma absoluta do ser" e, não importa se o compreenderam como subjetividade "vazia, solta, universal", ou subjetividade "plena, entranhada no mundo", nos dois casos trata-se de um "eu" "estrangeiro ao mundo" (MERLEAU-PONTY, 1991, p. 168, grifo nosso).

Se refizéssemos a questão: "Quem sou eu?" - uma das perguntas tautológicas mais comuns no cotidiano, a resposta comumente seria: "Eu sou eu mesmo" -, o que Pelbart traduz como "Eu sou idêntico a mim-mesmo" (2011, p. 1), seguindo a démarche de uma noção de identidade, unidade, universalidade. Nas palavras de Doel (2001), o sujeito é indivisível, cumprindo duas funções: individuação e universalização. Assim, é possível perceber que em muitos âmbitos filosóficos e científicos essa visão da subjetividade como sinônimo de identidade tem espaço.

No entanto, a solidez identitária desse sujeito não estaria em crise? Foucault, pelo menos desde Les mots et les choses [1966] e Qu'est-ce qu'un autor? [1969], com sua provocação acerca da morte do sujeito ou seu questionamento acerca da possibilidade de se falar deste, de autor ou de indivíduo, respectivamente (FOUCAULT, 1992, passim), já nos dera rastros de uma crise do eu, a partir do desfalecimento dos 
pilares instituídos acerca de um sujeito universal, unificado, intrapsíquico, individualizado em uma atmosfera de unificação, totalização (DOMÈNECH; TIRADO; GÓMEZ, 2001).

Ou seja, não soa estranho pensar que boa parte do imaginário comum compreende que a subjetividade é centrada em uma interioridade, no bojo da qual se acredita que a psique ou mente se localiza numa região intracorporal. Enfim, que haveria um topos mental estruturado e privado, intransferível e acessível aos profissionais "psi", por meio da linguagem, a lembrar da máxima psicanalítica em seus primórdios. Taylor (apud DOMÈNECH; TIRADO; GÓMEZ, 2001) afirma que essa concepção de situar a subjetividade em um espaço interior remonta a concepções cristãs (das quais nós, obviamente, estamos ainda entrelaçados).

Indubitavelmente, a Psicanálise foi uma das principais questionadoras do reduto irretocável do sujeito desde Descartes, problematizando a onipotência da razão consciente por meio da evidência dada a um inconsciente que age em nós e através de nós, sendo o que se chama de Eu (ego) apenas uma parte do nosso psiquismo (FREUD, 1977). No entanto, ainda com sua crítica a uma subjetividade presa à consciência, a Psicanálise esbarrou em uma pretensa universalidade das estruturas psíquicas, dos complexos, dos fantasmas.

Em outras palavras, embora indo de encontro a uma tradição filosófica inaugurada na Modernidade, que pautou as reflexões da subjetividade no pilar de uma identidade consciente, unificada, universalizada, intrapsíquica, interiorizada e individualizada, isso não foi suficiente para realizar um movimento centrífugo. Persistiu algo da ordem de uma suposta "Natureza Humana", de uma suposta subjetividade pré-existente, receptáculo de informações ou formatada em fases específicas: a adolescência, o édipo, a adultez de formatação de uma subjetividade identitária em um interior constituído, uma psique isolada. Se havia uma relação com o fora-de-si, era apenas como quem meramente está diante de um campo de informações a serem alocadas no dentro-de-si essencializado (DOMÈNECH; TIRADO; GÓMEZ, 2001).

A concepção de subjetividade aqui utilizada seguirá outra via, pautando-se sobretudo no conceito de "Processos de Subjetivação", criado pelo filósofo Gilles Deleuze e pelo psicanalista Félix Guattari. Nesse universo, as perspectivas identitárias, 
essencializadas, universais e unitárias de subjetividade perdem força para uma lógica poiética, marcada por linhas, fluxos nomadismos. Assim, enquanto boa parte da tradição filosófica afirmou a subjetividade numa filosofia da Identidade, Deleuze e Guattari (entre outros da sua geração, cada um ao seu modo) a colocam no hall da diferença. A seguir discutiremos conceitos fundamentais para a compreensão do conceito de processos de subjetivação na perspectiva deleuzoguattariana.

\section{Lógica arborescente ou rizomática?}

Para Deleuze e Guattari haveria uma certa lógica que poderíamos chamar de arborescente. Essa lógica está calcada em formar "órgãos", em "fixar um ponto", em estabelecer uma "ordem". Contra isso, trata-se de, extraindo da Biologia o conceito de Rizoma (raiz subterrânea que não tem início nem fim e cuja característica principal é seu crescimento ininterrupto por todos os lados), 1) perceber os princípios de "conexão e heterogeneidade", que versam acerca de uma fuga da ordem fixada para pensar as múltiplas conexões possíveis, onde não há um centro estável de onde seguem todas as extremidades, mas conexões que partem de todos os lados em uma espécie de descentramento heterogenético (DELEUZE; GUATTARI, 1995, p. 15).

Enumeremos outro princípio rizomático: 3) princípio de multiplicidade. Em relação ao objeto da nossa pesquisa, Deleuze e Guattari vão taxativamente abolir a ideia de sujeito. Se utilizamos, com o devido cuidado, uma multiplicidade real, por assim dizer; ou seja, sem cairmos em "pseudomultiplicidades arborescentes"; se a substantivamos mesmo, desaparecem sujeito (e objeto) e sobram, ao invés, "determinações, grandezas, dimensões". Coisas que, se crescem, também mudam 
(DELEUZE; GUATTARI, 1995, p. 16). A fórmula do múltiplo é " $n-1$ ". ${ }^{3}$ É sempre algo que se expande em uma "linha do fora"...

Em 4) princípio de ruptura a-significante estamos agora diante de um descrédito àquilo que implica "estruturas". Se falamos em sujeito, por exemplo, só se o entendermos menos como ponto fixo (natureza ou espírito) do que como "linhas". Essas linhas traçam territórios, é verdade. Mas o território não cessa de se desterritorializar no fora da imanência, de conectar-se com outras linhas e a cada momento traçar seus caminhos outros, suas "linhas de fuga". Dessa forma pode-se sair da lógica rígida da estrutura. Quer dizer, de tudo o que é "estratificado, territorializado, organizado, significado, atribuído etc." (DELEUZE; GUATTARI, 1995, p. 18). O rizoma pode sofrer rupturas em qualquer lugar, pode fazer ligações incessantes, e é por tal motivo que ele não se deixa formar-se por linhas de "segmentaridade dura" (mais a frente retomaremos melhor tais conceitos).

Bem diferentemente, há no rizoma uma extrapolação desses segmentos fortes, uma abertura para múltiplas possibilidades de ramificação. Sem início nem conclusão, o rizoma está sempre no meio, um milieu, como o cita Deleuze no livro Sobre o Teatro: “É no meio que há o devir, o movimento, a velocidade, o turbilhão. O meio não é uma média, e sim, ao contrário, um excesso. É pelo meio que as coisas crescem" (DELEUZE, 2010, p.25). Nesse intermezzo habitam os platôs, dos quais são feitos os rizomas. Platôs são regiões de constante intensidade que vibram multidirecionalmente sem um caminho pré-estabelecido aprioristicamente.

Os princípios 5 e 6 tratam da relação decalque e cartografia, sendo o primeiro relacionado à estrutura, ao eixo genético, à reprodução, à interpretação, ao modelo aprioristicamente estabelecido. O decalque se coloca como uma representação estática da realidade, uma pausa na multiplicidade em nome de uma organização e estabilização. Uma espécie de foto do rizoma que recorta, neutraliza seu movimento de multiplicação em uma representação hierárquica e topológica (DELEUZE;

\footnotetext{
${ }^{3}$ Zourabichvili, em obra que já se tornara célebre: Deleuze: une philosophie de l'evénement [2004] busca justamente mostrar que essa instância do "acontecimento", com todos os seus desdobramentos, poderia ser o ponto de síntese do filósofo francês. Cf. ZOURABICHVILI, 2016.

${ }^{4}$ Sobre a linha do fora ver o bom trabalho de Tatiana Salem Levy (2011, p. 102). Na parte específica sobre Deleuze ela mostra como há neste autor um lugar do fora dentro do qual só há lugar para o plano de imanência, muito embora haja sempre sobreposição de planos...
} 
GUATTARI, 1995). Ao contrário do decalque, o mapa da cartografia não busca uma fotografia estática da realidade em busca da representação e, sim, é "produzido, construído, sempre desmontável, conectável, reversível, modificável, com múltiplas entradas e saídas" (DELEUZE; GUATTARI, 1995, p. 32).

Eis que se pode estabelecer uma primeira diferença do conceito de processos de subjetivação às noções identitárias marcadas pela unidade, pela estabilidade, estruturação: a subjetivação na filosofia deleuzoguattariana é rizomática. E dito isso, subentende-se seus princípios de multiplicidade, de heterogênese. Nas palavras de Guattari (2010, p. 11), a subjetivação é plural e polifônica. O princípio de multiplicidade no terreno da subjetividade constitui uma distinção essencial na compreensão identitária, marcada pela unidade "Eu sou Eu", "Eu sou Eu-Mesmo" na mesmificação da qual a Modernidade vem se ancorando. A multiplicidade ou, como preferimos chamar, Multiplis/dade (como multiplicidade de si) é ancorada na diferença como gênese ontológica. Assim, ao invés de uma filosofia da identidade, falamos de uma Filosofia da Diferença.

\section{As máquinas desejantes}

No livro Qu'est-ce que la philosophie? [1991], Deleuze e Guattari tecem uma crítica às universalidades, afirmando que os Universais não explicam nada mas, ao invés, precisam ser explicados. Essa afirmação é de todo muito cara à subjetivação que, desde as noções modernas e o advento da Psicanálise, foi calcada numa noção de universalidade. Assim, é preciso desconfiar das tentativas de generalização de compreensões acerca da subjetivação.

Seguindo nessa direção, faz-se mister discutir um conceito complexo, no entanto fundamental para a teoria de Deleuze e Guattari: as máquinas desejantes. Há no livro L'Anti-Oedipe [1972] uma nova concepção de inconsciente, que foge às noções tradicionais da Psicanálise freudiana, calcadas no inconsciente "familialista"-neuróticoedipiano (na triangulação edipiana pai/mãe/filho-a, o "teatro" de Freud) e no inconsciente estruturalista de Lacan. 
Indo de encontro dessas concepções, Deleuze e Guattari (2010) tratam o inconsciente como uma fábrica, uma usina. Nesse caso, o seu modo de funcionamento é "Esquizo", compreendido como uma usina ou fábrica, que opera com máquinas desejantes, as quais produzem diretamente o Real. Para os autores há somente máquinas em todos os lugares. Máquinas com suas relações de conexão e corte de fluxos. L'Anti-Oedipe traz o exemplo de acoplamento entre máquinas: o seio é uma máquina-órgão que produz leite e a boca, como outra máquina acoplada a ela, que opera um corte no fluxo (DELEUZE; GUATTARI, 2010). Dessa forma, não há máquinas dissociadas, mas sempre conectadas, articuladas, e nossa subjetividade é uma bricolagem de diversas pequenas máquinas em relação de produto-produção com outras máquinas mais complexas.

O modo de funcionamento das máquinas desejantes se dá no desarranjo, o que confere o movimento de produção em processos de cortes e fluxos, conexões e rupturas. Para Deleuze e Guattari (2010, p. 20), ao passo que o inconsciente, lido como uma usina, é uma articulação de máquinas desejantes, o Édipo, com sua configuração de decalque e recorte das intensidades é uma repressão das máquinas desejantes e canalização para cenários intrafamiliares, para a falta.

Guattari, em entrevista de 1972 publicada no livro Pourparlers, de Deleuze [1990], afirma que Freud não ignora as máquinas desejantes, no entanto as submete a um corte, a uma repressão de acordo com a lógica representativa edipiana. Há, inclusive, uma provocação sobre Freud não gostar dos "esquizos", por sempre fugir da lógica transferencial. Daí que, no tocante à natureza humana, passa-se a ideia de que tais termos, homem e natureza, confrontam-se em uma lógica de causa-efeito, duas realidades ao invés de uma só, na perspectiva produtor-produto.

Por outro lado, no inconsciente maquínico tudo é produção: "produção de produções, de ações e de paixões, de distribuições e de marcações; produções de consumos, de volúpias, de angústias e de dores" (DELEUZE E GUATTARI, 2010, p.15). Ora, se, por um lado, há noções de desejo que imputam a este o negativo e a falta, capitaneando-o de acordo com a Lei (a psicanálise lacaniana acredita que existem desejos demais, sendo necessário canalizá-los a partir de anestesiamentos familialistas ou fantasmáticos - DELEUZE; PARNET, 1998; DELEUZE, 2016; LACAN, 1999), a noção de 
Desejo em Deleuze e Guattari (2010) é excesso e não falta, produção e não representação.

Para eles, nada falta ao desejo, não há falta de objeto que o mova. A falta nunca é anterior à produção desejante, não há produção que se organize a partir da falta. Ao contrário, a falta vem se propagar por máquinas sociais a partir de uma produção prévia (DELEUZE; GUATTARI, 2010). O que move o desejo é seu movimento nas maquinações com as quais estabelece relações. Assim, se para Deleuze e Guattari (2010) o desejo é produtivo, e produz real, não há uma separação entre produção social e de realidade, de um lado, e produção desejante, de outro. Há apenas liames entre essas duas produções. Como se as práticas sociais se duplicassem em práticas mentais, ou como se as práticas mentais se projetassem em práticas sociais.

Guattari declara em seu livro Caosmose (1992) a falência da representação universalista da subjetividade em nome de reivindicações cada vez mais singulares da subjetividade. O autor o faz por meio do conceito de heterogênese, evocando elementos plurais que interatuam na produção das subjetividades. Assim, cita os mecanismos semiológicos significantes presentes na família, na educação, arte, religião, esporte, meio ambiente; elementos fabricados pela indústria da mídia e cinema; dimensões semiológicas a-significantes que fogem às representações linguísticas.

Dessa forma, as tentativas de reducionismo da subjetividade em uma homogeneização universalizante, seja na Razão, como o fez Descartes, seja na relação familiar, como o fez a Psicanálise se mostram reducionistas por deixarem escapar as singularizações que fogem àquele modelo. Assim, qualquer explicação universalizante decai num processo de decalque, que recorta as multiplicidades em nome de uma explicação estável, estruturada.

Há no livro Micropolítica: Cartografias do Desejo (GUATTARI; ROLNIK, 1986) uma discussão salutar para o desenvolvimento do nosso estudo: a noção de uma produção de subjetividade que não é individuada, como se diz no senso comum e até em algumas perspectivas teóricas: "minha subjetividade" "subjetividade do indivíduo", subjetividade como sinônimo de identidade, em suas marcas idiossincráticas. Há, por 
outro lado, na perspectiva de Guattari e Rolnik (1986) uma subjetivação social, que se pode encontrar em todos os níveis de produção de consumo.

Todavia, essa subjetivação social não diz respeito a uma relação a um dentro intrapsíquico, o qual recebe do fora-social informações que moldam e formatam o dentro-individuado, como um recipiente, um mero simulacro "dentrificado" dos fatos sociais. A própria concepção de desejo no campo social postulada por Guattari e Deleuze em L'Anti-Oedipe [1972] já traz um questionamento do desejo e da subjetividade como centramento no indivíduo. Quer dizer, há uma compreensão do desejo a partir dos agenciamentos coletivos de enunciação, de um desejo inscrito e produzido no coletivo, de uma subjetivação produzida incessantemente no social, que em alguns casos pode se inscrever em um corpo individuado.

Coloca-se nesse escrito, como condição sine qua non, um certo empréstimo de pensamento à noção de formação coletiva do desejo e da subjetivação, sobretudo por ter como foco o estudo do microfascismo no campo da subjetivação, não buscando uma análise individualizada e sim dos processos de produção de subjetividades, processos estes que se dão nas vias coletivas. Há, sim, um descentramento do simesmo individualizado como território de produção de subjetividades, mas isso se faz pela via da processualidade das subjetividades fabricadas e modeladas constantemente, sejam elas subjetividades "individuais" (dito assim apenas em termos didáticos), mas também grupais, institucionais. Por exemplo, há processos de subjetivação em um partido político, em um bairro, uma empresa, um hospital, processos de produção de subjetividades que circulam e se intercruzam constantemente.

Dessa forma, o descentramento da subjetividade da individualidade opera um processo até então pouco trabalhado, a saber: o surgimento de subjetividades grupais, institucionais. Não como uma identidade grupal, como se pode ouviu falar nas ciências sociais, mas como processos de subjetivação grupais com fluxos incessantes de diferença em seu movimentos subjetivos.

Uma discussão necessária para a compreensão da subjetivação é o do conceito de dispositivo de Michel Foucault, retomado por Deleuze no livro Deux régimes de fous [2003]. Para o filósofo, o dispositivo é antes de tudo um conjunto plurilinear, uma 
meada composta de linhas de naturezas diferentes, traçando processos em desequilíbrio, variações e derivações. Esses dispositivos têm três dimensões, a saber: Saber, Poder, Subjetivação. Acerca da dimensão da subjetivação, Deleuze (2016) afirma à luz de Foucault que a Subjetividade não é nem um Saber, nem um Poder (apesar de se ver atravessada por esses vetores), mas sim um processo de subjetivação, que incide sobre grupos ou pessoas, subtraindo do entrelaçar de forças.

Em suma, cada dispositivo é uma multiplicidade, no qual se operam processos em devir, de "outramentos", reiterando a perspectiva do movimento da diferença em detrimento das análises do ego e da identidade. Sendo sempre necessário distinguir o que estamos sendo (gerúndio escolhido pela via não estável do verbo) e o que estamos por devir.

Pode-se afirmar ainda nesse sentido que, segundo os autores, as múltiplas linhas de um dispositivo se repartem em dois grupos: linhas de estratificação ou de sedimentação e linhas de atualização ou de criatividade. Processos nos quais nos cabe falar nas linhas de segmentaridade e nos processos de territorialização, desterritorialização e reterritorialização, que discutiremos de forma mais pormenorizada a seguir.

Retomemos aquilo que ficamos de novamente evocar. Acerca das linhas supracitadas, Deleuze e Guattari (1996) citam no 3o volume do seu livro Mille Plateaux: Capitalisme et schizophrénie três tipos de linhas que atravessam os processos de subjetivação, a saber: as de segmentaridade dura ou molares, onde os estratos representam uma maleabilidade menor como classe social, gênero; as de segmentaridade maleável ou moleculares, que representam níveis maiores de desestratificação, proporcionando movimentos rizomáticos, esquizos, de devir que produzem transmutações; e as linhas de fuga, que dizem respeito às rupturas com os estratos e produzem desestratificações absolutas.

Que se diga, porém, como observação de suma importância, que não há em todos aqueles estratos uma segregação nítida entre as três linhas, todas estão conectadas (inclusive podendo situá-las na lógica de "co-funcionamento" das máquinas desejantes), elas se atravessam na composição dos rizomas na sociedade, onde as relações de força se intercruzam e se bifurcam pela ótica dos encontros e pela 
micropolítica dos processos de afetar e ser afetado. Tecendo diferenças entre as linhas de segmentaridade dura e maleável, pode-se afirmar que as linhas duras dependem das máquinas que operam cortes binários homem $\mathrm{x}$ mulher, rico $\mathrm{x}$ pobre, enquanto as maleáveis já permitem multiplicidades com maiores dimensões, onde o homem pode devir-mulher, por exemplo.

Retomando uma discussão já apresentada aqui, podemos relacionar as linhas de segmentaridade duras às arborescências, as quais mesmo se dicotomizando afirmam o Uno, e as linhas de segmentaridade maleáveis ao rizoma, que afirmam as multiplicidades (DELEUZE; GUATTARI, 1996). Não há, todavia, um julgamento moral na oposição entre segmentaridade dura e maleável, molar e molecular, não há o lado bonzinho do molecular por exemplo.

No que diz respeito às linhas de fuga, os autores supracitados afirmam que nestas não se trata de "fugir do mundo". "Como? Pela arte, talvez; ou então fugir às nossas responsabilidades. Não; a coisa é mesmo invertida: antes de fugir do mundo, 'fazê-lo fugir"' (ROCHA, 2008, p. 45). Significaria isso afirmar os processos de descodificação e desestratificação. Rupturas, fissuras, rompimentos que produzem mudanças absolutas e intensivas, não categorizáveis às lógicas das linhas duras ou maleáveis. São linhas imprevisíveis, de naturezas diferenciadas, que precisam ser criadas em meio às linhas duras e maleáveis.

As linhas de fuga têm a capacidade de fazer fugir nos corpos o desejo em seu potencial de se libertar de aprisionamentos a estratificações, proporcionando aos processos de subjetivação uma via de experimentação não decaída em armadilhas identitárias. Na ruptura com o que está posto, os corpos se abrem para outras possibilidades (CASSIANO; FURLAN, 2013). É aí que reside a dimensão criativa da subjetivação, as quais em meio às estratificações relativas ou absolutas se abrem fugas para outras possibilidades. No entanto, o mesmo cuidado que coube às linhas duras e maleáveis, cabe nas linhas de fuga: a de romantizá-las ou colocá-las como meramente positivo num maniqueísmo que não cabe às teorias que embasam essa discussão. Há, inclusive, a possibilidades de as linhas de fuga serem capturadas, cooptadas por máquinas e se metamorfosearem em linhas de abolição ou de destruição (DELEUZE, 1980). 
Retomemos uma vez mais aquele tema que, na teoria de Deleuze e Guattari, transversaliza toda a discussão dos processos de subjetivação e se relaciona diretamente com a lógica das linhas supracitadas: os movimentos de territorialização, desterritorialização e reterritorialização. Com base na apropriação filosófica que eles fazem da Geografia, os autores pensam o conceito de Território no sentido de uma relação com a terra, mas, especificamente acerca da subjetivação, Guattari (1993) cria o conceito de Territórios Existenciais ou Subjetivos, dizendo respeito a um conjunto de projetos, comportamentos, investimentos, desejo, processos sociais, culturais, estéticos e cognitivos em torno de uma estabilidade, uma apropriação, "fechada sobre si mesma" (GUATTARI; ROLNIK, 1986, p. 323). Valendo a ressalva de que os territórios podem ser também grupais, coletivos, institucionais.

No entanto, um território não é permanente, posto que é tensionado a destruir, lançar-se em um movimento de ruptura, denominado por Deleuze e Guattari (2010) de desterritorialização. Nesse sentido, as linhas de fuga destroem os territórios, fazem fugir de seu fechamento em si. Onde a territorialização emana uma predominância da repetição frente a diferença, a desterritorialização produz rupturas nos territórios, engendrando a diferenciação.

O movimento de territorialização, desterritorialização e reterritorialização é ininterrupto e indissociável, acontecendo em graus e velocidades diferentes de acordo com os termos e abertura dos corpos. Não há aqui também julgamentos de valor que elencam heróis ou vilões nesses processos, há reterritorializações de extrema potência e desterritorializações que podem desembocar em linhas de morte e de aprisionamento.

É válido ressaltar que ninguém se desterritorializa sozinho e, sim, no mínimo em dois termos, sempre em um encontro, numa relação de forças. O processo de reterritorialização é uma criação de um novo território completamente diferente do anterior, posto que nunca se pode considerar a reterritorialização como o retorno a uma "organização inicial", como a volta do mesmo; no máximo o novo território pode preservar alguns elementos do território anterior, mas com mudanças.

Um conceito central para a compreensão do movimento dos processos de subjetivação é o conceito de agenciamento, que para Deleuze e Guattari (1995) 
comporta duas faces, a saber: o agenciamento coletivo de enunciação e agenciamento maquínico dos corpos. No entanto, a separação entre eles não é nítida, posto que o agenciamento maquínico, enquanto agenciamento social de desejo, também é um agenciamento coletivo de enunciação. Para Deleuze e Guattari (1997) os agenciamentos produzem desestratificação dos meios, extraindo deles um território, pois todo agenciamento é primordialmente territorial, sendo, pois, necessário descobrir a territorialidade de um agenciamento. Cabe ao agenciamento duas perguntas: qual sua territorialidade e quais são as pontas de desterritorialização.

No entanto, os agenciamentos também se segmentam de acordo com a maleabilidade e rigidez de suas linhas, bifurcam-se, conectam-se. Nas conexões produz territorializações, mas os agenciamentos também têm seus movimentos de desterritorializações, onde as linhas de fuga e os desejos e enunciações se metamorfoseiam (DELEUZE; GUATTARI, 1975).

No quinto volume do livro Mille Plateaux Deleuze e Guattari propõem dois eixos no agenciamento, a saber, horizontal e vertical. Sendo que cada eixo tem duas partes, o que origina o que se chama da "tetravalência do agenciamento", composto pelos seguintes elementos: "1) conteúdo e expressão; 2) territorialidade e desterritorialização." (DELEUZE; GUATTARI, 1997, p. 194).

$\mathrm{Na}$ tetravalência, no eixo horizontal temos o eixo do conteúdo, onde o Agenciamento Maquínico de Desejo diz respeito ao agenciamento dos corpos, do plano das afecções, das paixões e do encontro, relativo ao jogo pragmático de ações, afetações e distribuições espaciais, onde os corpos reagem uns sobre os outros; e o eixo de expressão, onde o Agenciamento Coletivo de Enunciação diz respeito aos processos de expressão e enunciação sempre coletivos, relativo a um sistema semiótico, com uma produção discursiva e de signos, de transformações incorpóreas (DELEUZE; GUATTARI, 1975; HUR, 2012).

Segundo Hur (2012), no eixo vertical há em uma parte lados territoriais do agenciamento, constituídos por processos de estabilização, consolidação, fixação, ou seja, territorialização e, em outra, picos de desterritorialização, com a ação das linhas de fuga, com o abandono de um território, colocando em funcionamento processos de criação e transmutação. 
Sendo retomados e melhor especificados os conceitos de agenciamento, territorialização, desterritorialização e reterritorialização cabe situar um conceito central para a compreensão dos processos de subjetivação, o do Ritornelo, criado por Deleuze e Guattari (1980) e apresentado no 4으 volume do livro Mille Plateaux. Fugindo da via unitária que os conceitos geralmente assumem, o Ritornelo se apresenta de maneira plural, ora de uma forma, ora de outra, ora... ora... ora...Não se tratando de movimentos sucessivos, categoricamente organizados, há três movimentos que funcionam de maneira simultânea e que se misturam. Os autores descrevem o ritornelo como um "agenciamento territorial" e como um "ethos" (DELEUZE; GUATTARI, 1980, p.103).

No tocante aos movimentos supracitados, 1) ora se vai do caos a um centro de estabilidade, de um território com a busca de um ponto; o que se denomina componentes direcionais ou infra-agenciamento 2) ora se organiza uma estabilidade, encontra-se um centro, um ponto, um ritmo em meio ao caos, suficiente para construir um território. Nesse sentido, há uma busca por uma dimensão a ser habitada, um espaço íntimo que deixa de fora o caos, chamado de componentes dimensionais; 3 ) ora se sai do agenciamento territorial na direção de agenciamentos outros, outros lugares, o que se pode chamar componentes de passagem ou de fuga.

Destarte, percebemos a partir dos movimentos do Ritornelo que a relação entre diferença e repetição se dá não como simples oposição, mas como processos que se intercruzam e engendram novos territórios por meio do acoplamento de novos agenciamentos. Ademais, no que diz respeito ao que se conhece por "indivíduo" ou "sujeito" é preciso salientar que, ao invés da estabilidade, que geralmente supõem, há uma encruzilhada de componentes, linhas, fluxos, vetores, forças. Fazendo fugir a perspectiva centrada em uma via estática, o que já representa, por outro lado, uma espécie de assujeitamento em que a diferença do modo de produção incessante da subjetivação que tem no devir, no outramento, na diferença sua principal característica é cooptada pela identidade, pela repetição (GUATTARI; ROLNIK, 1986). 


\section{À guisa de conclusão}

Os processos de subjetivação se fazem em encontros, não apenas encontros humanos, mas também encontros não humanos. Há um processo de subjetivação em curso no encontro de uma pessoa com seu cão, com uma música, com uma pedra preciosa, com um ambiente, com um objeto. Esses encontros se dão sempre em movimentos de empréstimo, de associação, de ruptura, de engendramento e cortes.

Para Guattari e Rolnik (1986), o que se diz sobre um indivíduo já é um produto serializado, modelado, fruto de uma produção de massa. Não são de forma alguma um entidade constituída intrapsiquicamente, uma topografia "egóica". Nem tampouco, por outro lado, uma entidade social ou agente grupal estabelecida. Para os autores, quando se diz processos de subjetivação já se diz respeito a um processo de descentralização de qualquer explicação unificadamente constituída. Nessa direção, o conceito de rizoma ganha corpo, por afirmar uma lógica da multiplicidade em contraposição ao Uno, como vimos.

Nos processos de subjetivação há o funcionamento de máquinas de natureza "extra pessoal, extra individual, infra-humana, infrapsíquica e infrapessoal". Ratificando, uma espécie de co-funcionamento de fatores de produção das subjetividades de maneira incessante e não finalizada (GUATTARI; ROLNIK, 1986, p.31). Nesse processo de produção de subjetividades podem interatuar máquinas de ordens plurais, sem que qualquer um desses tenha uma relação hierárquica ou de classificação temporal, como já fora dito anteriormente. Em suma, quaisquer encontros em que o desejo circule em seus fluxos e cortes, produzindo interferências no plano da memória, da inteligência, dos afetos, do inconsciente. Isso nos faz compreender a heterogeneidade dos componentes maquínicos de engendramento de subjetividades. Podendo ser desde aqueles ligados à escola, arte, esporte, aos ligados pela mídia, cinema, entre outros (GUATTARI, 2010).

É necessário considerar, porém, que há processos de reprodução e antiprodução no desejo e na subjetivação. Nestes, determinadas máquinas intentam não mais a produção da singularidade, da diferença, mas o assujeitamento, repetição ou aquilo que Guattari e Rolnik (1986) chamaram de subjetividades serializadas, levando em conta as subjetividades produzidas em série. Assim, há um rebaixamento 
da capacidade mutante da subjetivação em nome da repetição e da mesmidade identitária.

Em suma, a recusa de uma perspectiva identitária, afinada com todos os processos de individuação engendrados pela sociedade (a massificação e uniformização de valores e desejos é sua face mais visível) fizeram Deleuze e Guattari criarem uma trama de conceitos transversais importantes. Assim, indo da Filosofia à Geografica, da Psicanálise à Biologia, evocaram o papel criador de todos os agenciamentos naturais e "cósmicos", mostrando que a subjetividade não pode ser entendida como uma estrutura, senão como um locus inevitável de encontros e transformações incessantes.

\section{Referências}

CASSIANO, M.; FURLAN, R. "O Processo De Subjetivação segundo a Esquizoanálise". Psicologia \& Sociedade, 25(2), 373-378, 2013.

DELEUZE, G. Conversações. São Paulo: Ed. 34. 1990.

. Sobre Teatro: Um manifesto de menos - O esgotado. Compilação de Roberto Machado. Rio de Janeiro: Zahar. 2010.

. Dois regimes de Loucos. Tradução de Guilherme Ivo. São Paulo: Ed. 34. 2016

DELEUZE, G.; GUATTARI, F. O que é a filosofia? Tradução de Bento Prado Júnior e Alberto Muñoz. Rio de Janeiro. Editora 34.1993.

- Mil platôs: capitalismo e esquizofrenia. Tradução de Aurélio Guerra e Célia Costa. Vol.1 Rio de Janeiro: Ed. 34, 1995

Mil Platôs: capitalismo e esquizofrenia. Tradução de Aurélio (et. al). Vol. 3. Rio de Janeiro: Ed. 34. 1996.

. O Anti-Édipo: capitalismo e esquizofrenia. Tradução de Luiz B. L. Orlandi. São

Paulo: Ed. 34. 2010.

DELEUZE, G; PARNET, C. Diálogos. São Paulo: Escuta: 1998.

DESCARTES, René. Meditações. Tradução de J. Guinsburg e Bento Prado Júnior. 2a ed. São Paulo: Abril Cultural, 1979.

DOEL, M. "Corpos sem órgãos: esquizoanálise e desconstrução". In: SILVA, T. (org.) Nunca fomos humanos: nos rastros do sujeito. Belo Horizonte: Autêntica, 2001. 
DOMÈNECH, M; TIRADO, F.; GÓMEZ. "A dobra: psicologia e subjetivação". In: SILVA, T. (org.) Nunca fomos humanos: nos rastros do sujeito. Belo Horizonte: Autêntica, 2001.

FOUCAULT, Michel. O que é um autor? Tradução de António Fernando Cascais e Edmundo Cordeiro. Lisboa: Veja/Passagens, 1992.

As palavras e as coisas: uma arqueologia das Ciências Humanas. Tradução de Salma Tannus Muchail. 6ạ ed. São Paulo: Martins Fontes, 1992.

FREUD, S. A interpretação dos sonhos. In: FREUD, S. Obras psicológicas completas de Sigmund Freud. Rio de Janeiro: Imago, 1977. v. 4-5.

GUATTARI, Félix. Caosmose: um novo paradigma estético. Rio de Janeiro: Editora 34, 1992.

As três ecologias. Tradução de Maria Cristina Bittencourt. Campinas: Papirus, 1993.

GUATTARI, F., \& ROLNIK, S. Micropolítica: cartografias do desejo (4 ed.) Petrópolis: Editora Vozes. 1986.

HUR, D. "O Dispositivo de Grupo Na Esquizoanálise: Tetravalência e Esquizodrama". Revista do NESME, 9(1), pp 1-60, 2012.

LACAN, J. O seminário: livro 5: as formações do inconsciente. Rio de Janeiro: Jorge Zahar, 1999.

LEVY, Tatiana Salem. A experiência do fora: Blanchot, Foucault e Deleuze. Rio de Janeiro: Civilização Brasileira, 2011

MERLEAU-PONTY. Fenomenologia da percepção. Tradução de Reginaldo di Piero. Rio de Janeiro: Freitas Bastos, 1971.

1991.

Signos. Tradução de Maria Ermantina Pereira. São Paulo: Martins Fontes,

PELBART, P. Poéticas da Alteridade, 2011. Disponível em: $<$ https://revistas.pucsp.br/index.php/bordas/article/download/7734/5663>. Acesso em: 17 de mar. de 2018.

ROCHA, Jorge. Gilles Deleuze: as aventuras do conceito. Feira de Santana: UEFS/NEF, 2008.

ZOURABICHVILI, François. Deleuze: uma filosofia do acontecimento. Tradução de Luiz B. L. Orlandi. São Paulo: Editora 34, 2016. 